\title{
Management of Very Old Patients in Intensive Care Units
}

\author{
Xin Ding1,\#, Hui Lian ${ }^{2, \#, ~ X i a o t i n g ~ W a n g ~}{ }^{1,2, *}$, Chinese Critical Ultrasound Study Group \\ ${ }^{1}$ Department of Critical Care Medicine, Peking Union Medical College Hospital, Chinese Academy of Medical \\ Sciences and Peking Union Medical College, Beijing, China. \\ ${ }^{2}$ Department of Health Care, Peking Union Medical College Hospital, Chinese Academy of Medical Sciences \\ and Peking Union Medical College, Beijing, China.
}

[Received July 19, 2020; Revised September 9, 2020; Accepted September 14, 2020]

\begin{abstract}
The global population is aging and the demand for critical care wards increasing. Aging is associated not only with physiological and cognitive vulnerability, but also with a decline in organ function. A new topic in geriatric care is how to appropriately use critical care resources and provide the best treatment plan for very old patients (VOPs). Our special geriatric intensive care unit has admitted nearly 500 VOPs. In this review, we share our VOP treatment strategy and summarize the key points as "ABCCDEFGHI bundles." The aim is to help intensivists to provide more comprehensive therapy for VOPs in intensive care units.
\end{abstract}

Key words: very old patients, treatment strategy, ABCCDEFGHI bundles, intensive care unit

The global population is rapidly aging. By 2050, the proportion of the global population aged $>60$ years will have increased from $12 \%$ in 2013 to an estimated $21 \%$ [1]. The rapid expansion of the elderly population has increased the demand for critical care wards [2]. Although there is no clear consensus, patients $>80$ years are generally defined as "very old patients" (VOPs) in the field of critical care medicine. In the past 20 years, the number of VOPs in intensive care units (ICUs) has increased substantially and continues to grow.

Aging is a complex transition that includes physiological and cognitive vulnerability, which make the individual more prone to diseases and acute medical events, leading to further reduction in reserve capacities, loss of functional independency, and ultimately to death[3]. It has been demonstrated that frailty is an independent risk factor for mortality [4]. The Clinical Frailty Scale is currently used to assess the severity of frailty. Frailty is common among hospitalized VOPs. Measurement of frailty in this population can help doctors to increase the efficiency of clinical activities and improve the prognosis of patients at risk [5].

Aging is associated with a decline in the immune system, termed "immune senescence." Both cellular and serological responses are affected during the aging process. Multiple changes damage the immune body cells, disrupting immune regulation [6]. In addition, chronic diseases associated with aging can also lead to mild inflammation and increased levels of circulating cytokines and pro-inflammatory markers, leading to prolonged reaction time to infection [7]. As a result, VOPs are more susceptible to infections than younger patients.

Because of these characteristics, older people are more likely to get infections and have a poor prognosis. The most common reasons for ICU admission are postoperative organ failure and sepsis [8]. Research on

*Correspondence should be addressed to: Dr. Wang Xiaoting, Department of Health Care and Department of Critical Care Medicine, Peking Union Medical College Hospital, Chinese Academy of Medical Sciences, Beijing 100730, China. Email: wangxiaoting@pumch.cn. \# these authors contributed equally to this work.

Copyright: (C) 2020 Ding X. et al. This is an open-access article distributed under the terms of the Creative Commons Attribution License, which permits unrestricted use, distribution, and reproduction in any medium, provided the original author and source are credited. 
outcomes in critically ill patients with sepsis worldwide shows that hospital mortality increases with age. VOPs have twice the mortality as that of patients aged $\leq 50$ years (49.3\% vs. $25.2 \%$, p < 0.05)[8]. Despite the high intensity of care and prolonged hospitalization, the total mortality of VOPs in the ICU is high. Recent observational studies have found an ICU mortality of between $15 \%$ and $25 \%$ [9]. Therefore, how to use critical care resources appropriately and provide the best treatment plan for VOPs is a new topic in the development of critical care medicine.

Our special geriatric ICU has admitted nearly 500 VOPs. In this review, we share our treatment strategy for VOPs and summarize the key points, which we call "ABCCDEFGHI bundles" (Table 1), based on recent positive results and our own experiences. We hope that these will inform future clinical practice.

\section{Airway: Protective reflex impairment is an important cause of aspiration pneumonia}

Aspiration pneumonia is an increasingly prevalent problem in older people and is associated with high mortality $[10,11]$. For patients aged $\geq 65$ years in the United States, the incidence of aspiration pneumonia was 30.9 cases per 10,000 people, and the mortality was $11.3 \%$ in 2012, which was two times higher than in patients aged $<65$ years [12]. Age $>65$ years is an independent predictor of in-hospital mortality among patients admitted for aspiration pneumonia.
There is a pronounced decrease in the protective reflex of the airway (i.e., swallowing and cough reflexes) with age[13]. Pontoppidan et al found that the threshold of the protective airway reflex increases 6-fold from the second to the eighth and ninth decades of life, which explains why silent tracheal aspiration seems to be more frequent in older people [14]. The protective airway reflex can be further depressed by injudicious use of depressant drugs in elderly patients [15]. Furthermore, age-related changes in hyoid bone position may also contribute to reduced swallowing safety and aspiration. The sensory component of protective reflexes, which involves the sensory cortex, seems to be more vulnerable to aging than the motor component; therefore, treatments that enhance sensory nerve terminals and sensory cortical areas may be useful [16].

Although there is no consensus on standard protocols for the prevention of aspiration pneumonia, several measures should be applied. The maintenance of good oral hygiene is important and medications that affect salivary flow or cause sedation are best avoided if possible. The use of $\mathrm{H} 2$ blockers and proton-pump inhibitors should be minimized [17]. Tube feeding is a last resort and the use of gastrojejunostomy inserted through percutaneous endoscopic gastrostomy may be a good choice [18]. There is no evidence that any specific antibacterial agent has superior efficacy, and the use of broad-spectrum antibiotics can result in multiresistancy [19].

Table 1. Key points of the management of VOPs in ICU.

\begin{tabular}{ll}
\hline $\begin{array}{l}\text { Airway } \\
\text { Breathing }\end{array}$ & $\begin{array}{l}\text { Protective reflex impairment is an important cause of aspiration pneumonia. } \\
\text { Cardiovascular factors should be paid close attention in patients with dyspnea. } \\
\text { Circulation } \\
\begin{array}{l}\text { Comorbidities and } \\
\text { factors of the circulatory system. } \\
\text { Delirium }\end{array}\end{array}$ \\
$\begin{array}{l}\text { A strong predictive index of mortality. } \\
\text { Enteral nutrition }\end{array}$ & Monitoring and non-pharmacological prevention is more important. \\
Frailty & It is important especially for malnourished VOPs. \\
Geriatrician & A risk factor that should not be neglected. \\
Homeostasis & Comprehensive evaluation is helpful for the rehabilitation of VOPs. \\
Infection & The cornerstone of treatment for critically ill VOPs.
\end{tabular}

Breathing: Cardiovascular factors should be paid close attention in patients with dyspnea

The mortality rate for elderly patients receiving mechanical ventilation is approximately $53 \%$ [20]. Thus, the management of breathing abnormalities in elderly patients is very important. Aging is associated with changes in respiratory functions such as lung volume and gas exchange. The total lung capacity remains constant in adults, but from age 20 years, vital capacity decreases by $26 \mathrm{ml} /$ year for men and $22 \mathrm{ml} /$ year for women [21]. Thus, residual volume increases with age. There are changes in 
the ratio of residual volume and total lung capacity, forced expiratory volume in $1 \mathrm{~s}$, and forced vital capacity [22]. Owing to a disproportion between ventilation and blood flow, arterial oxygen pressure decreases. As lung compliance decreases with age, there is a greater tendency for airway collapse, especially in the gravity-dependent region [23]. Abnormally early airway collapse leads to both reduced abilities to generate normal expiratory pressures and increased expiratory resistance.

Dyspnea is one of the most common respiratory complaints and is frequently reported by elderly patients [24]. The estimated prevalence of dyspnea is $21 \%$ for patients aged 65 years [25] and 30\% for those aged $\geq 80$ years [26]. Dyspnea causes substantial disability and may lead to mortality [27]. There are many causes of dyspnea, including respiratory system abnormalities, cardiovascular disease, diaphragmatic dysfunction, and endocrine diseases [28]. Several studies indicate that, in addition to the focus on respiratory diseases, more attention should be paid to cardiovascular diseases [27, 29].

The aging process is a major contributor to cardiovascular system changes in older people [30, 31]. Although resting left ventricular diastolic function does not change, left ventricular diastolic function alters substantially [32]. Myocardial velocities measured using tissue doppler imaging of the mitral annulus during diastole fall progressively with age; in addition there is an increase in left ventricular diastolic stiffness that correlates with advancing age [33]. There is a steep increase in the prevalence of heart failure in older adults with normal left ventricular systolic function [34]. A significant reduction in early left ventricular filling may leave the left ventricle less distended and result in a failure of the Frank-Starling mechanism, together with an ageassociated reduction in left ventricular compliance, which can easily cause increases in left atrial and left ventricular end diastolic pressure and lead to pulmonary congestion and edema. Thus, age-related changes in cardiovascular function, and the high prevalence of hypertension and coronary artery disease in the older population, combine to reduce cardiovascular reserve and increase the risk of heart failure in older adults, which is a main cause of dyspnea [35]. As 24-hour urine output also decreases with age [36], a conservative fluid management strategy should be administrated, which may attenuate the age-associated increase in ventilator-associated mortality [37].

\section{Circulation: Cardiac rhythms abnormalities, especially atrial fibrillation are often the deteriorating factors of the circulatory system}

With aging, the heart undergoes specific changes [38]. Although resting heart rate is not affected by age, the incidence of arrhythmias increases [39-41]. At the cellular level, reduced $\mathrm{Ca}^{2+}$ reuptake in myocytes leads to prolongation of action potentials, and several complex changes in calcium-related ion currents and other factors slow cellular reactions responsible for controlling the periodicity of heartbeats. Furthermore, the general increase in fibrous content and the calcification process in cardiac tissue may lead to dysfunction in the atrioventricular node, and an increase in the risk of atrioventricular block [42].

Atrial fibrillation (AF) is found in approximately 3\% to $4 \%$ of subjects aged $>60$ years, a rate 10 -fold higher than that of the general adult population [40]. With age, increased myocardial stiffness leads to slower ventricle filling and reduced cardiac filling during the early diastolic phase, which increases the importance of the active filling phase during atrial contraction. Therefore, older patients with AF may have stable decompensated heart failure that is associated with increased mortality [39, 43]. The management of elderly patients with AF should focus on the presence of hemodynamic compromise, direct therapy to address the (reversible) causes of AF, control of heart rate, and prevention or treatment of heart failure and ischemia $[44,45]$. Emphasis should be placed on optimizing the benefits and reducing the risks of anticoagulation in this important and expanding group of patients [46].

\section{Comorbidities and multimorbidities: a strong predictive index of mortality}

The proportion of patients with comorbidities and the number of comorbidities (combination of additional diseases beyond an index disorder) per patient increase with age; the mean number of comorbidities per patient is 3.6 in patients aged $\geq 85$ years [47]. The prevalence of more than one comorbid illness is substantially higher in ICU patients aged $\geq 65$ years, and is associated with higher in-hospital [36, 48] and long-term mortality rates [49]. The most common comorbidities in the ICU are cardiovascular diseases such as hypertension and cardiac failure, respiratory diseases such as chronic obstructive pulmonary disease, diseases associated with a compromised immune system, metastatic cancer, hepatic disease, end-stage kidney disease, and hematologic malignancy $[36,50]$. The Charlson comorbidity index has been validated for critically ill patients and predicts mortality.

According to one systematic review, multimorbidity (the coexistence of more than two chronic diseases) affects $55 \%$ to $98 \%$ of the elderly population. The main consequences of multimorbidity are functional impairment, poor quality of life, and high health care costs [51]. A retrospective study of 442,962 ICU patients 
concluded that, unlike the comorbidities mentioned above, angina, dysrhythmias, acute myocardial infarction, and drug overdose are the most common multimorbidities in the ICU. To fully evaluate a patient, a multimorbidity index (MMI) has been developed that can help to assess the patient prognosis [52].

With age, physiological changes lead to a reduction in reserve capacities. Advanced age is associated with changes in respiratory physiology (loss of elastic lung tissue, increased anteroposterior chest diameter, reduced muscle strength, and sensitivity of respiratory centers to hypoxemia and hypercapnia), leading to an increased risk of acute respiratory failure and mortality [53]. Furthermore, the proliferative capacity and the number of immune cells renewed from hematopoietic stem cells decline owing to progressive telomere shortening. This results in gradual immune dysfunction, or immune senescence. Immune senescence not only increases the risk of sepsis, but also leads to more severe infection and may also be related to higher mortality [54]. Overall, comorbidities and multimorbidities complicate disease conditions and affect outcomes in the older population.

\section{Delirium: Monitoring and non-pharmacological prevention is more important}

Delirium is an acute disorder of attention and cognition in elderly people that is common, serious, costly, underrecognized, and often fatal $[55,56]$. Nearly $30 \%$ of older patients (aged $>65$ years) experience delirium at some point during hospitalization, and $40 \%$ of older patients admitted to the ICU have delirium [57]. The development of delirium depends on complex interrelationships between patient vulnerability, several predisposing factors, and exposure to noxious insults or predisposing factors. The leading risk factors are dementia or cognitive impairment, functional impairment, visual impairment, and history of alcohol misuse [58]. The gradual accumulation of permanent damage to neurons, dendrites, receptors, and microglia, and the effects of cerebrovascular disease or head trauma, can render older people susceptible to delirium when biologically stressed, especially in the presence of underlying cognitive impairment [59]. Delirium is also a risk factor for prolonged duration of mechanical ventilation, longer ICU stay, and mortality [60, 61]. Early recognition and diagnosis can improve patient prognosis. Thus, delirium monitoring should be an important routine clinical task. However, delirium is usually underdiagnosed [62]. Many delirium screening tools have been developed, such as the Confusion Assessment Method for the ICU (CAM-ICU) [63] and the Intensive Care Delirium Screening Checklist (ICDSC) [64]. In our hospital, we use the CAM-ICU to monitor delirium, because it can be completed in less than 1 minute and the pooled values for sensitivity and specificity are $80 \%$ and $95.9 \%$, respectively, although the measure has several limitations [64].

Delirium and dementia frequently coexist in older patients. Dementia is a leading risk factor for delirium and delirium is an independent risk factor for subsequent development of dementia [65]. The differentiation between delirium and dementia is of crucial importance, as their assessment and clinical management are distinct. There are many signs and symptoms that can differentiate the two conditions, such as onset, duration, consciousness, speech, and causes [66].

Multicomponent non-pharmacological risk factor approaches are the most effective strategies to prevent delirium, and include discontinuation or dose reduction of anticholinergic and psychoactive drugs; family or companion involvement for reorientation and comfort; non-pharmacological approaches to sleep and relaxation; creation of a quiet, soothing, warm environment; and pain management $[65,67]$. There is no convincing evidence that pharmacological prevention or treatment is effective for this condition. Drugs should be used only in severely agitated patients for whom interruption of essential medical therapies or self-harm is a risk, or in patients with extremely distressing psychotic symptoms [68].

\section{Enteral nutrition: It is important especially for malnourished VOPs}

Malnutrition affects $12 \%$ to $45 \%$ of hospitalized older patients [69]. In critically ill patients, malnutrition and negative protein-energy balance are associated with longer ICU length of stay, mortality, rate of acquired infection, and duration of mechanical ventilation $[70,71]$. Several diseases and impairments may directly influence the balance between nutritional needs and intake, including age, frailty, cognitive and physical decline, depressive symptoms, emotional variations, poor oral health, and socioeconomic changes [72,73]. Even in cases of adequate nutrient and energy intake, the nutritional status of older adults can be impaired by compromised nutrient metabolism, drug-nutrient interactions, or altered nutrient needs [74].

Structured assessment and documentation of patient nutritional status are needed to ensure sufficient attention and intervention regarding nutrition. The Subjective Global Assessment (SGA), the Mini Nutritional Assessment (MNA), and the Geriatric Nutrition Risk Index (GNRI) are nutritional assessment tools developed specifically for elderly people; however, there is no single tool that can be considered the universal gold standard for diagnosis [69].

The feeding route can modulate splanchnic flow, as 
demonstrated in a study by Gatt et al. Postprandial superior mesenteric artery blood flow substantially increased with oral and enteral feeding, but decreased with parenteral feeding [75]. As oral intake is often impossible in older patients in the ICU, enteral nutrition is the recommended feeding route; however, it is often unable to fully provide nutritional needs [76, 77]. Parenteral nutrition is recommended if enteral nutrition is not feasible [70].

\section{Frailty: A risk factor that should not be neglected}

It is very important to be able to predict which VOPs will benefit from ICU admission and have a chance of longterm survival with good quality of life. In general ICU patients, severity of illness and comorbidities at admission and treatment limitations are associated with outcome [49]; however, in VOPs, the concept of frailty seems to be more important than illness severity or traditional comorbidity measures [78]. Frailty is a clinical state of increased susceptibility owing to age-associated decline in reserve and function in a wide range of physiological systems. The concept is increasingly incorporated into prediction models to adjust for the effect of biological age as opposed to chronological age. Common signs and symptoms of frailty include fatigue, weight loss, weakness, low activity level, slow motor performance, and cognitive loss [79].

Frailty is a disorder that involves several interrelated physiological systems; the brain, endocrine system, immune system, and skeletal muscles are the organ systems that have been most studied in research on the development of frailty [80]. Fried et al found a nonlinear relation between the number of abnormal systems and frailty, independent of age and comorbidity, and the number of abnormal systems was more predictive of frailty than abnormalities in any particular systems[81].

There is currently no consensus on the best approach to screen or identify patients with prehospital frailty on admission to the ICU setting. The Clinical Frailty Scale (CFS), the Frailty Index (FI), and the Frailty Phenotype (FP) are common scales used to predict outcomes. The CFS views frailty as a multidimensional risk state that ranges from 1 (very fit) to 9 (terminally ill); scores of 5 to 8 indicate frailty. In a study of 5132 critically ill patients aged $\geq 80$ years, frailty (CFS score $>4$ ) was present in $43.1 \%$ and was independently related to ICU admission (22.2\%) and 30-day mortality (35.8\%) [82]. The FP assumes that frailty is a biological syndrome resulting from cumulative decline across multiple physiological systems, and contains five criteria (shrinking, weakness, slowness, low-level physical activity, and self-reported exhaustion). An FP score $\geq 3$ is a risk factor for ICU mortality [83]. The perfusion index, which measures health deficit accumulation, may also help to improve critical care outcome prediction in older adults [84]. A meta-analysis of 10 observational studies and 3030 ICU patients showed that frailty is associated with higher hospital mortality and long-term mortality, and that frail patients are less likely to be discharged home than fit patients [85].

\section{Geriatrician care: Comprehensive evaluation is helpful for the rehabilitation of VOPs}

Geriatric expertise is usually not available on a regular basis in other wards, and it is not usual for a geriatrician consultation to be sought when deciding whether to discharge an elderly patient [86]. However, owing to their expertise in multimorbidity and acute stress in older patients, geriatricians can provide a more comprehensive assessment of older patients that may lead to better care and orientation decisions for those patients. Recently, geriatrician involvement has been found to provide a survival benefit in many other groups; furthermore, specialized geriatric ICU care may greatly improve survival in older adults, compared with general ICU patients [84]. One small-scale, single-center study illustrated the benefits of geriatric intervention for functional dependency in 45 older patients after ICU discharge, and showed that physical function was usually recovered rapidly [87].

Including a geriatrician in shared decision making for critically ill older patients may improve their outcomes. However, there are no large-scale studies that support this hypothesis. The effect of including a geriatrician in the assessment of octogenarians in the ICU still needs to be demonstrated using randomized trials [88].

\section{Homeostasis: The cornerstone of treatment for critically ill VOPs}

In elderly patients, physiological changes associated with aging increase the likelihood of fluid and electrolyte disorders [89]. The most important changes are a decrease in glomerular filtration rate, decreased urinary concentrating ability, and narrowed limits for the excretion of water, sodium, potassium, and acid. Critically ill older patients may lose the ability to maintain homeostasis, making them more susceptible to hyponatremia, hypernatremia, volume depletion, volume overload, hyperkalemia, and metabolic acidosis. Therefore, it is important to be aware of potential electrolyte abnormalities in elderly patients to prevent adverse outcomes.

Hypernatremia and hyponatremia are the most common electrolyte abnormalities in elderly patients, and 
both are associated with high mortality rate[90]. Delirium, seizures, and coma are common symptoms of hyponatremia [91], and consciousness disorders and confusion can be associated with hypernatremia [92]. Owing to the widespread administration of fluids or diuretics in the ICU, hypernatremia is more common, especially in elderly patients [93]. Extreme care must be taken to avoid excessively rapid correction or overcorrection of hypernatremia, as it increases the risk of iatrogenic cerebral edema, with possibly serious consequences. Many medications prescribed to elderly patients can interfere with urinary excretion of potassium. It must be recognized that both hypokalemia and hyperkalemia are associated with life-threatening cardiac arrhythmia, and the risks and benefits of using large doses of diuretics or potassium-sparing agents should be weighed cautiously when making treatment decisions.

Alterations in calcium, magnesium, and phosphorus homeostasis are also very common in elderly critically ill patients. Concentrations of these electrolytes tend to be elevated owing to renal insufficiency. However, poor nutrition intake and use of some medications can lead to deficiency states. Therefore, levels of these electrolytes should be carefully monitored in elderly critically ill patients.

\section{Infection: Prevention and early recognition are more important}

A national survey conducted in China in 2018 showed that sepsis-related mortality accounted for up to $12.6 \%$ of total mortality. In VOPs, the mortality rate is nearly 50 times that of their younger adult counterparts (3136.5 vs. 66.7 per 100,000 population, p<0.0001) [50]. Hospitalacquired infection in VOPs is life threating and preventable. Drawing on our experiences, we will summarize the predisposing factors in VOPs in terms of open access owing to intubation and immune senescence.

Many mechanisms account for immune senescence, including alterations in the mucosal lining barriers [94], loss of the proliferative capacity of immune cells [95], impaired signal transduction, and decreased antibody response [96-98]. Moreover, the risk of infection in VOPs increases sharply on hospitalization, because of the use of tubes [99, 100]. The 2017 Extended Prevalence of Infection in Intensive Care (EPIC) III study, which was conducted worldwide, showed that the most common sites of infection in ICUs are the respiratory tract, abdomen, and bloodstream [101], mainly owing to mechanical ventilation, impaired intestinal barrier, and catheterization. Of infections in VOPs, ventilationassociated pneumonia, urinary tract infections, and catheter-related bloodstream infections are preventable and controllable. In our hospital, constant evaluation of hand hygiene compliance, strict assessment of sterile operations, and airway management have reduced ventilation-associated pneumonia and catheter-related bloodstream infections infection rates by $90 \%$. It is also important to remove all unnecessary catheters as early as possible. Another cause of iatrogenic infection is the overuse of antibiotics. Clostridium difficile infection is a typical example. our ward has set up an antibiotic guidance and monitoring group to improve the use of antibiotics.

Care strategies for ICU patients must take into account the unique characteristics of VOPs. First, they require early identification of infection. VOPs may not show infection-specific symptoms or signs. Low-grade temperature elevation, increased confusion, and anorexia may be the earliest signs, though they do not have a high positive predictive value [102]. For some elderly patients, exacerbation of underlying diseases (e.g., AF) may be a major sign of infection. Thus, comprehensive assessment of the underlying condition helps to identify the infection early. Second, the simple principle of "start low, go slow" applies to the administration of most drugs, but not to antibiotics. Some antibiotics with concentrationdependent activity work best when the drug concentration is well above the minimum inhibitory concentration, which is more important for successful treatment in older adults than in younger adults $[103,104]$. For VOPs with severe infections, it is important to use the highest dose within a safe range when administering antibiotics for the first time.

From the end of 2019, a pandemic caused by severe acute respiratory syndrome coronavirus 2 (SARS-CoV2), termed COVID-19, has spread globally. Older adults are more likely to have severe disease. A study based on data from mainland China found that the hospitalization rate for COVID-19 increased with age, from $1 \%$ for individuals aged 20-29 years to $18 \%$ for those aged $>80$ years [105]. Mortality is also associated with older age. A report from the Chinese Center for Disease Control and Prevention showed that case fatality rates are $8 \%$ for individuals aged $70-79$ years and $15 \%$ for those aged $\geq 80$ years [106]. In the United States, $80 \%$ of deaths occur in individuals aged $\geq 65$ years [107]. This may be related to the poor immune function of older adults, which weakens their response to pathogens [108]. Age, Sequential Organ Failure Assessment (SOFA) score, Acute Physiology and Chronic Health Evaluation (APACHE) score, platelet count $<125 \times 10^{9} / \mathrm{L}$, d-dimer, creatinine $>133 \mu \mathrm{mol} / \mathrm{L}$, interleukin-6, and lung consolidation on admission are independent risk factors for disease severity among older patients with COVID-19 [109]. Older age is a relative contraindication for the use of some advanced life support equipment, such as extracorporeal membrane oxygenation. Therefore, the key treatment strategy 
principle for these patients after COVID-19 diagnosis is to provide aggressive support therapy (e.g., respiratory support and nutrition support) to prevent deterioration, rather than treat the condition when it becomes severe. Furthermore, strengthening protection and control strategies for older adults is a priority.

This paper has focused on systemic therapy for VOPs. However, whether VOPs can benefit from ICU care remains controversial [110], and there is no consensus among clinicians on the triage process [111]. This is the main therapeutic difference between VOPs and younger adult patients. During the COVID-19 pandemic, doctors have often taken old age into consideration when deciding on the provision of life-sustaining measures, and conservative treatment plans are generally adopted for elderly patients. In most countries, decisions about whether to administer risky or traumatic procedures such as tracheal intubation mainly depend on the patient's living will and family choices [112]. A systematic review concluded that age and illness severity were most strongly associated with ICU admission refusal, especially during periods of reduced bed availability [113]. Advanced age is an independent risk factor for do-not-resuscitate orders. Whether this is ethical needs to be explored in depth.

Age alone does not predict mortality, even in the most vulnerable VOPs. The most important factor in determining if ICU admission is appropriate for an elderly patient is to consider whether or not intensive care is individualized and comprehensive. The ABCCDEFGHI bundles summarize our thoughts and suggestions about intensive care for critically ill VOPs and may provide new ideas for the diagnosis and comprehensive management of VOPs during clinical practice.

\section{Acknowledgment}

This study is supported by Key Project of Central Health Care Scientific Research (2020ZD08).

\section{Conflict of interest}

The authors declare that there is no conflict of interest.

\section{References}

[1] Beard JR, Officer A, de Carvalho IA, Sadana R, Pot AM, Michel JP, et al. (2016). The World report on ageing and health: a policy framework for healthy ageing. Lancet, 387:2145-2154.

[2] Ihra GC, Lehberger J, Hochrieser H, Bauer P, Schmutz $\mathrm{R}$, Metnitz B, et al. (2012). Development of demographics and outcome of very old critically ill patients admitted to intensive care units. Intensive Care Med, 38:620-626.

[3] Guidet B, Vallet H, Boddaert J, de Lange DW,
Morandi A, Leblanc G, et al. (2018). Caring for the critically ill patients over 80 : a narrative review. Ann Intensive Care, 8:114.

[4] Laake J, Dybwik K, Flaatten H, Fonneland I, Kvåle R, Strand KJAaS (2010). Impact of the post-World War II generation on intensive care needs in Norway. Acta anaesthesiologica Scandinavica, 54:479-484.

[5] Fronczek J, Polok K, Nowak-Kózka I, Włudarczyk A, Górka J, Czuczwar M, et al. (2018). Frailty is associated with an increased mortality among patients $\geq 80$ years old treated in Polish ICUs. Anaesthesiol Intensive Ther, 50:245-251.

[6] Gavazzi G, Herrmann F, Krause KJCidaopotIDSoA (2004). Aging and infectious diseases in the developing world. Clin Infect Dis, 39:83-91.

[7] Franceschi C, Bonafè M, Valensin S, Olivieri F, De Luca M, Ottaviani E, et al. (2000). Inflamm-aging. An evolutionary perspective on immunosenescence. Annals of the New York Academy of Sciences, 908:244-254.

[8] Al-Dorzi H, Tamim H, Mundekkadan S, Sohail M, Arabi YJBa (2014). Characteristics, management and outcomes of critically ill patients who are 80 years and older: a retrospective comparative cohort study. BMC Anesthesiol, 14:126.

[9] Heyland D, Cook D, Bagshaw SM, Garland A, Stelfox HT, Mehta S, et al. (2015). The Very Elderly Admitted to ICU: A Quality Finish? Crit Care Med, 43:13521360.

[10] Marik PE (2001). Aspiration pneumonitis and aspiration pneumonia. N Engl J Med, 344:665-671.

[11] DM D, care WRJJoc (2015). Aspiration pneumonia: a review of modern trends. J Crit Care, 30:40-48.

[12] Wu CP, Chen YW, Wang MJ, Pinelis E (2017). National Trends in Admission for Aspiration Pneumonia in the United States, 2002-2012. Ann Am Thorac Soc, 14:874-879.

[13] Won HK, Yoon SJ, Song WJ (2018). The doublesidedness of cough in the elderly. Respir Physiol Neurobiol, 257:65-69.

[14] Pontoppidan H, Beecher HK (1960). Progressive loss of protective reflexes in the airway with the advance of age. JAMA, 174:2209-2213.

Lewis KP, Stanley GD (1999). Pharmacology. Int Anesthesiol Clin, 37:73-86.

[16] Ebihara S, Ebihara T, Kohzuki M (2012). Effect of aging on cough and swallowing reflexes: implications for preventing aspiration pneumonia. Lung, 190:29-33. Luk JK, Chan DK (2014). Preventing aspiration pneumonia in older people: do we have the 'knowhow'? Hong Kong Med J, 20:421-427.

[18] Lawinski M, Gradowski L, Bzikowska A, Goszczynska A, Jachnis A, Forysinski K (2014). Gastrojejunostomy inserted through PEG (PEG-J) in prevention of aspiration pneumonia. Clinical nutrition complication in dysphagic patients. Pol Przegl Chir, 86:223-229.

[19] Bowerman TJ, Zhang J, Waite LM (2018). Antibacterial treatment of aspiration pneumonia in older people: a systematic review. Clin Interv Aging, 
13:2201-2213.

[20] Gattinoni L, Protti A, Caironi P, Carlesso EJCcm (2010). Ventilator-induced lung injury: the anatomical and physiological framework. Crit Care Med, 38:S539-548.

[21] Muiesan G, Sorbini CA, Grassi V (1971). Respiratory function in the aged. Bull Physiopathol Respir (Nancy), 7:973-1009.

[22] Brody A, Johnson J, Townley R, Herrera H, Snider D, Campbell JJTArord (1974). The residual volume: predicted values as a function of age. Am Rev Respir Dis, 109:98-105.

[23] Anthonisen N, Danson J, Robertson P, Ross WJRp (1969). Airway closure as a function of age. Respir Physiol, 8:58-65.

[24] Gentzler ER, Derry H, Ouyang DJ, Lief L, Berlin DA, $\mathrm{Xu} \mathrm{CJ}$, et al. (2019). Underdetection and Undertreatment of Dyspnea in Critically Ill Patients. Am J Respir Crit Care Med, 199:1377-1384.

[25] Eakin EG, Kaplan RM, Ries AL (1993). Measurement of dyspnoea in chronic obstructive pulmonary disease. Qual Life Res, 2:181-191.

[26] Hegendorfer E, Vaes B, Mathei C, Van Pottelbergh G, Degryse JM (2017). Correlates of dyspnoea and its association with adverse outcomes in a cohort of adults aged 80 and over. Age Ageing, 46:994-1000.

[27] Barberger-Gateau P, Nejjari C, Tessier JF, Dartigues JF (1995). Assessment of disability and handicap associated with dyspnoea in elderly subjects. Disabil Rehabil, 17:83-89.

[28] Mahler DA (2017). Evaluation of Dyspnea in the Elderly. Clin Geriatr Med, 33:503-521.

[29] Berraho M, Nejjari C, El Rhazi K, Tessier JF, Dartigues JF, Barberger-Gateau P, et al. (2013). Dyspnea: a strong independent factor for long-term mortality in the elderly. J Nutr Health Aging, 17:908912.

[30] Costantino S, Paneni F, Cosentino F (2016). Ageing, metabolism and cardiovascular disease. J Physiol, 594:2061-2073.

[31] de Almeida A, Ribeiro TP, de Medeiros IA (2017). Aging: Molecular Pathways and Implications on the Cardiovascular System. Oxid Med Cell Longev, 2017:7941563.

[32] Oxenham H, Sharpe N (2003). Cardiovascular aging and heart failure. Eur J Heart Fail, 5:427-434.

[33] Downes TR, Nomeir AM, Smith KM, Stewart KP, Little WC (1989). Mechanism of altered pattern of left ventricular filling with aging in subjects without cardiac disease. Am J Cardiol, 64:523-527.

[34] Barfuss SB, Butts R, Knecht KR, Prada-Ruiz A, Lal AK (2019). Outcomes of Myocarditis in Patients with Normal Left Ventricular Systolic Function on Admission. Pediatr Cardiol, 40:1171-1174.

[35] Rich MW (1997). Epidemiology, pathophysiology, and etiology of congestive heart failure in older adults. J Am Geriatr Soc, 45:968-974.

[36] Bagshaw SM, Webb SA, Delaney A, George C, Pilcher D, Hart GK, et al. (2009). Very old patients admitted to intensive care in Australia and New
Zealand: a multi-centre cohort analysis. Crit Care, 13:R45.

[37] Herbert JA, Valentine MS, Saravanan N, Schneck MB, Pidaparti R, Fowler AA, 3rd, et al. (2016). Conservative fluid management prevents ageassociated ventilator induced mortality. Exp Gerontol, 81:101-109.

[38] Flaatten H, Skaar E, Joynt GM (2018). Understanding cardiovascular physiology of ageing. Intensive Care Med, 44:932-935.

[39] Strait JB, Lakatta EG (2012). Aging-associated cardiovascular changes and their relationship to heart failure. Heart Fail Clin, 8:143-164.

[40] Bosch NA, Cimini J, Walkey AJ (2018). Atrial Fibrillation in the ICU. Chest, 154:1424-1434.

[41] Obas V, Vasan RS (2018). The aging heart. Clin Sci (Lond), 132:1367-1382.

[42] Chiao YA, Rabinovitch PS (2015). The Aging Heart. Cold Spring Harb Perspect Med, 5:a025148.

[43] Shaver CM, Chen W, Janz DR, May AK, Darbar D, Bernard GR, et al. (2015). Atrial Fibrillation Is an Independent Predictor of Mortality in Critically Ill Patients. Crit Care Med, 43:2104-2111.

[44] Michelena HI, Ezekowitz MD (2000). Approach to management of the patient over age 75 with atrial fibrillation. Cardiol Rev, 8:9-16.

[45] Moskowitz A, Chen KP, Cooper AZ, Chahin A, Ghassemi MM, Celi LA (2017). Management of Atrial Fibrillation with Rapid Ventricular Response in the Intensive Care Unit: A Secondary Analysis of Electronic Health Record Data. Shock, 48:436-440.

[46] Atzema CL, Singh SM (2018). Acute Management of Atrial Fibrillation: From Emergency Department to Cardiac Care Unit. Cardiol Clin, 36:141-159.

[47] de Rooij SE, Govers A, Korevaar JC, Abu-Hanna A, Levi M, de Jonge E (2006). Short-term and long-term mortality in very elderly patients admitted to an intensive care unit. Intensive Care Med, 32:1039-1044. [48] Zampieri FG, Colombari F (2014). The impact of performance status and comorbidities on the shortterm prognosis of very elderly patients admitted to the ICU. BMC Anesthesiol, 14:59.

[49] Stavem K, Hoel H, Skjaker SA, Haagensen R (2017). Charlson comorbidity index derived from chart review or administrative data: agreement and prediction of mortality in intensive care patients. Clin Epidemiol, 9:311-320.

[50] Weng L, Zeng XY, Yin P, Wang LJ, Wang CY, Jiang $\mathrm{W}$, et al. (2018). Sepsis-related mortality in China: a descriptive analysis. Intensive Care Med, 44:10711080.

[51] Marengoni A, Angleman S, Melis R, Mangialasche F, Karp A, Garmen A, et al. (2011). Aging with multimorbidity: a systematic review of the literature. Ageing Res Rev, 10:430-439.

[52] Min H, Avramovic S, Wojtusiak J, Khosla R, Fletcher $\mathrm{RD}$, Alemi F, et al. (2017). A Comprehensive Multimorbidity Index for Predicting Mortality in Intensive Care Unit Patients. J Palliat Med, 20:35-41. [53] Zeleznik J (2003). Normative aging of the respiratory 
system. Clin Geriatr Med, 19:1-18

[54] Martin S, Perez A, Aldecoa C (2017). Sepsis and Immunosenescence in the Elderly Patient: A Review. Front Med (Lausanne), 4:20.

[55] Oh ES, Fong TG, Hshieh TT, Inouye SK (2017). Delirium in Older Persons: Advances in Diagnosis and Treatment. JAMA, 318:1161-1174.

[56] Kukreja D, Gunther U, Popp J (2015). Delirium in the elderly: Current problems with increasing geriatric age. Indian J Med Res, 142:655-662.

[57] Inouye SK, Westendorp RG, Saczynski JS (2014). Delirium in elderly people. Lancet, 383:911-922.

[58] Perkisas SM, Vandewoude MF (2015). Ramelteon for prevention of delirium in hospitalized older patients. JAMA, 313:1745-1746.

[59] Cole MG (2004). Delirium in elderly patients. Am J Geriatr Psychiatry, 12:7-21.

[60] Salluh JI, Wang H, Schneider EB, Nagaraja N, Yenokyan G, Damluji A, et al. (2015). Outcome of delirium in critically ill patients: systematic review and meta-analysis. BMJ, 350:h2538.

[61] Klein Klouwenberg PM, Zaal IJ, Spitoni C, Ong DS, van der Kooi AW, Bonten MJ, et al. (2014). The attributable mortality of delirium in critically ill patients: prospective cohort study. BMJ, 349:g6652.

[62] Morandi A, Piva S, Ely EW, Myatra SN, Salluh JIF, Amare D, et al. (2017). Worldwide Survey of the "Assessing Pain, Both Spontaneous Awakening and Breathing Trials, Choice of Drugs, Delirium Monitoring/Management, Early Exercise/Mobility, and Family Empowerment" (ABCDEF) Bundle. Crit Care Med, 45:e1111-e1122.

[63] Ely EW, Margolin R, Francis J, May L, Truman B, Dittus R, et al. (2001). Evaluation of delirium in critically ill patients: validation of the Confusion Assessment Method for the Intensive Care Unit (CAM-ICU). Crit Care Med, 29:1370-1379.

[64] Barr J, Fraser GL, Puntillo K, Ely EW, Gelinas C, Dasta JF, et al. (2013). Clinical practice guidelines for the management of pain, agitation, and delirium in adult patients in the intensive care unit. Crit Care Med, 41:263-306.

[65] Nazemi AK, Gowd AK, Carmouche JJ, Kates SL, Albert TJ, Behrend CJ (2017). Prevention and Management of Postoperative Delirium in Elderly Patients Following Elective Spinal Surgery. Clin Spine Surg, 30:112-119.

[66] Fong TG, Davis D, Growdon ME, Albuquerque A, Inouye SK (2015). The interface between delirium and dementia in elderly adults. Lancet Neurol, 14:823-832.

[67] Trogrlic Z, van der Jagt M, Bakker J, Balas MC, Ely EW, van der Voort PH, et al. (2015). A systematic review of implementation strategies for assessment, prevention, and management of ICU delirium and their effect on clinical outcomes. Crit Care, 19:157.

[68] Neufeld KJ, Yue J, Robinson TN, Inouye SK, Needham DM (2016). Antipsychotic Medication for Prevention and Treatment of Delirium in Hospitalized Adults: A Systematic Review and Meta-Analysis. J Am Geriatr Soc, 64:705-714.
[69] Abd Aziz NAS, Teng N, Abdul Hamid MR, Ismail NH (2017). Assessing the nutritional status of hospitalized elderly. Clin Interv Aging, 12:1615-1625.

[70] Thibault R, Pichard C (2010). Nutrition and clinical outcome in intensive care patients. Curr Opin Clin Nutr Metab Care, 13:177-183.

[71] Rasheed S, Woods RT (2013). Malnutrition and associated clinical outcomes in hospitalized patients aged 60 and older: an observational study in rural Wales. J Nutr Gerontol Geriatr, 32:71-80.

[72] van Bokhorst-de van der Schueren MA, LontermanMonasch S, de Vries OJ, Danner SA, Kramer MH, Muller M (2013). Prevalence and determinants for malnutrition in geriatric outpatients. Clin Nutr, 32:1007-1011.

[73] Favaro-Moreira NC, Krausch-Hofmann S, Matthys C, Vereecken C, Vanhauwaert E, Declercq A, et al. (2016). Risk Factors for Malnutrition in Older Adults: A Systematic Review of the Literature Based on Longitudinal Data. Adv Nutr, 7:507-522.

[74] Bernstein M (2017). Nutritional Needs of the Older Adult. Phys Med Rehabil Clin N Am, 28:747-766.

[75] Gatt M, MacFie J, Anderson AD, Howell G, Reddy BS, Suppiah A, et al. (2009). Changes in superior mesenteric artery blood flow after oral, enteral, and parenteral feeding in humans. Crit Care Med, 37:171176.

[76] Singer P, Blaser AR, Berger MM, Alhazzani W, Calder PC, Casaer MP, et al. (2018). ESPEN guideline on clinical nutrition in the intensive care unit. Clin Nutr, 38:48-79.

[77] Berger MM, Reintam-Blaser A, Calder PC, Casaer M, Hiesmayr MJ, Mayer K, et al. (2019). Monitoring nutrition in the ICU. Clin Nutr, 38:584-593.

[78] Boumendil A, Somme D, Garrouste-Orgeas M, Guidet B (2007). Should elderly patients be admitted to the intensive care unit? Intensive Care Med, 33:1252.

[79] Fried LP, Tangen CM, Walston J, Newman AB, Hirsch C, Gottdiener J, et al. (2001). Frailty in older adults: evidence for a phenotype. J Gerontol A Biol Sci Med Sci, 56:M146-156.

[80] Walston J, Hadley EC, Ferrucci L, Guralnik JM, Newman AB, Studenski SA, et al. (2006). Research agenda for frailty in older adults: toward a better understanding of physiology and etiology: summary from the American Geriatrics Society/National Institute on Aging Research Conference on Frailty in Older Adults. J Am Geriatr Soc, 54:991-1001.

[81] Fried LP, Xue QL, Cappola AR, Ferrucci L, Chaves P, Varadhan R, et al. (2009). Nonlinear multisystem physiological dysregulation associated with frailty in older women: implications for etiology and treatment. J Gerontol A Biol Sci Med Sci, 64:1049-1057.

[82] Flaatten H, De Lange DW, Morandi A, Andersen FH, Artigas A, Bertolini G, et al. (2017). The impact of frailty on ICU and 30-day mortality and the level of care in very elderly patients $(>/=80$ years $)$. Intensive Care Med, 43:1820-1828.

[83] Le Maguet P, Roquilly A, Lasocki S, Asehnoune K, Carise E, Saint Martin M, et al. (2014). Prevalence and 
impact of frailty on mortality in elderly ICU patients: a prospective, multicenter, observational study. Intensive Care Med, 40:674-682.

[84] Zeng A, Song X, Dong J, Mitnitski A, Liu J, Guo Z, et al. (2015). Mortality in Relation to Frailty in Patients Admitted to a Specialized Geriatric Intensive Care Unit. J Gerontol A Biol Sci Med Sci, 70:1586-1594.

[85] Muscedere J, Waters B, Varambally A, Bagshaw SM, Boyd JG, Maslove D, et al. (2017). The impact of frailty on intensive care unit outcomes: a systematic review and meta-analysis. Intensive Care Med, 43:1105-1122.

[86] Guidet B, De Lange DW, Christensen S, Moreno R, Fjolner J, Dumas G, et al. (2018). Attitudes of physicians towards the care of critically ill elderly patients - a European survey. Acta Anaesthesiol Scand, 62:207-219.

[87] Somme D, Andrieux N, Guerot E, Lahjibi-Paulet H, Lazarovici C, Gisselbrecht M, et al. (2010). Loss of autonomy among elderly patients after a stay in a medical intensive care unit (ICU): a randomized study of the benefit of transfer to a geriatric ward. Arch Gerontol Geriatr, 50:e36-40.

[88] Flaatten H, de Lange DW, Artigas A, Bin D, Moreno $\mathrm{R}$, Christensen S, et al. (2017). The status of intensive care medicine research and a future agenda for very old patients in the ICU. Intensive Care Med, 43:13191328.

[89] El-Sharkawy AM, Sahota O, Maughan RJ, Lobo DN (2014). The pathophysiology of fluid and electrolyte balance in the older adult surgical patient. Clin Nutr, 33:6-13.

[90] Schlanger LE, Bailey JL, Sands JM (2010). Electrolytes in the aging. Adv Chronic Kidney Dis, 17:308-319.

[91] Yong TY, Huang JE, Lau SY, Li JY (2011). Severe hyponatremia and other electrolyte disturbances associated with indapamide. Curr Drug Saf, 6:134-137.

[92] Knochel JP (1982). Neuromuscular manifestations of electrolyte disorders. Am J Med, 72:521-535.

[93] Khow KS, Lau SY, Li JY, Yong TY (2014). Diureticassociated electrolyte disorders in the elderly: risk factors, impact, management and prevention. Curr Drug Saf, 9:2-15.

[94] Gomez CR, Boehmer ED, Kovacs EJ (2005). The aging innate immune system. Curr Opin Immunol, 17:457-462.

[95] Weiskopf D, Weinberger B, Grubeck-Loebenstein B (2009). The aging of the immune system. Transpl Int, 22:1041-1050.

[96] Panda A, Qian F, Mohanty S, van Duin D, Newman FK, Zhang L, et al. (2010). Age-associated decrease in TLR function in primary human dendritic cells predicts influenza vaccine response. J Immunol, 184:2518-2527.

[97] Lefebvre JS, Haynes L (2012). Aging of the CD4 T Cell Compartment. Open Longev Sci, 6:83-91.

[98] Scholz JL, Diaz A, Riley RL, Cancro MP, Frasca D (2013). A comparative review of aging and B cell function in mice and humans. Curr Opin Immunol,
25:504-510.

[99] Peron EP, Hirsch AA, Jury LA, Jump RL, Donskey CJ (2013). Another setting for stewardship: high rate of unnecessary antimicrobial use in a veterans affairs long-term care facility. J Am Geriatr Soc, 61:289-290.

[100] Wang L, Lansing B, Symons K, Flannery EL, Fisch J, Cherian $\mathrm{K}$, et al. (2012). Infection rate and colonization with antibiotic-resistant organisms in skilled nursing facility residents with indwelling devices. Eur J Clin Microbiol Infect Dis, 31:17971804.

[101] Vincent JL, Sakr Y, Singer M, Martin-Loeches I, Machado FR, Marshall JC, et al. (2020). Prevalence and Outcomes of Infection Among Patients in Intensive Care Units in 2017. JAMA, 323:1478-1487.

[102] Caterino JM, Kline DM, Leininger R, Southerland LT, Carpenter CR, Baugh CW, et al. (2019). Nonspecific Symptoms Lack Diagnostic Accuracy for Infection in Older Patients in the Emergency Department. J Am Geriatr Soc, 67:484-492.

[103] Kollef MH (2003). The importance of appropriate initial antibiotic therapy for hospital-acquired infections. Am J Med, 115:582-584.

[104] Drusano GL, Preston SL, Fowler C, Corrado M, Weisinger B, Kahn J (2004). Relationship between fluoroquinolone area under the curve: minimum inhibitory concentration ratio and the probability of eradication of the infecting pathogen, in patients with nosocomial pneumonia. J Infect Dis, 189:1590-1597.

[105] Verity R, Okell LC, Dorigatti I, Winskill P, Whittaker C, Imai N, et al. (2020). Estimates of the severity of coronavirus disease 2019: a model-based analysis. Lancet Infect Dis, 20:669-677.

[106] Wu Z, McGoogan JM (2020). Characteristics of and Important Lessons From the Coronavirus Disease 2019 (COVID-19) Outbreak in China: Summary of a Report of 72314 Cases From the Chinese Center for Disease Control and Prevention. JAMA, 323:12391242.

[107] Team CC-R (2020). Severe Outcomes Among Patients with Coronavirus Disease 2019 (COVID-19) - United States, February 12-March 16, 2020. MMWR Morb Mortal Wkly Rep, 69:343-346.

[108] Guo Y, Liu X, Deng M, Liu P, Li F, Xie N, et al. (2020). Epidemiology of COVID-19 in older persons, Wuhan, China. Age Ageing, 49:706-712.

[109] Li T, Lu L, Zhang W, Tao Y, Wang L, Bao J, et al. (2020). Clinical characteristics of 312 hospitalized older patients with COVID-19 in Wuhan, China. Arch Gerontol Geriatr, 91:104185.

[110] Leblanc G, Boumendil A, Guidet B (2017). Ten things to know about critically ill elderly patients. Intensive Care Med, 43:217-219.

[111] Boumendil A, Angus DC, Guitonneau AL, Menn AM, Ginsburg C, Takun K, et al. (2012). Variability of intensive care admission decisions for the very elderly. PLoS One, 7:e34387.

[112] Al-Dorzi HM, Tamim HM, Mundekkadan S, Sohail MR, Arabi YM (2014). Characteristics, management and outcomes of critically ill patients who are 80 years 
and older: a retrospective comparative cohort study. BMC Anesthesiol, 14:126.

[113] Sinuff T, Kahnamoui K, Cook DJ, Luce JM, Levy MM, Values E, et al. (2004). Rationing critical care beds: a systematic review. Crit Care Med, 32:1588-1597. 